Journal of Economics and Behavioral Studies

Vol. 6, No. 10, pp. 829-839, October 2014 (ISSN: 2220-6140)

\title{
Volatility characteristics of stocks underlying Exchange Traded Funds in South Africa
}

\author{
Justice Matarutse, *Mabutho Sibanda \\ University of KwaZulu-Natal, Durban, South Africa \\ *sibandam@ukzn.ac.za
}

\begin{abstract}
Exchange Traded Funds (ETFs), since their inception, are now taking a foothold in emerging markets. The study measures price volatility in ETFs and their underlying stocks before and after ETF inception so as to provide new evidence of the volatility implications of ETFs for financial markets. The analysis focuses on the Johannesburg Stock Exchange (JSE) SatrixTop40 ETF and its components using an EGARCH $(1,1)$ model. The analysis focuses on leverage effects, absolute size of volatility innovations and volatility persistence, and concludes that these volatility characteristics have changed and/or increased after the Satrix Top40 ETF introduction on the JSE.
\end{abstract}

Keywords: Exchange Traded Funds; volatility; emerging markets; Johannesburg Stock Exchange

\section{Introduction}

In recent years, Exchange Traded Funds (ETFs) have become an investment vehicle of choice for investors that seek prompt, low-cost exposure to broad equity market indices, industry sectors and other asset classes. The trend, gaining momentum, is for fund managers, institutional investors and individuals to now look to ETFs as a way of implementing their investment strategies. Trading in these securities has become an important source of information dissemination in global equity markets, and this study examines how volatility information flows across the JSE Satrix Top40 ETF and its largest component stocks. In light of the exponential growth in these securities, regulators and market observers have raised concerns that ETFs may generate an additional source of stock market volatility hence the need to conduct this study. ETFs as a financial innovation have impacted capital markets in a significant and positive way during their short time of existence. This high growth of ETFs has not gone unnoticed by regulators though; a lot of attention is now being focused on the unseen risks inherent in ETFs and the threat that they pose to the stability of financial markets, e.g. the NASDAQ, which suffered as a result of the Flash Crash of 6 May 2010 (SEC, 2010). The volatility effects of the presence of ETFs on the Johannesburg Stock Exchange (JSE) are the core of what is investigated in this study. This follows on from studies conducted by Lin and Chiang (2005) on the Taiwanese Stock Exchange relating to stock price volatility brought about by the introduction of ETFs into the market. Previous studies on the volatility effects of ETFs on capital markets have considered the function of index arbitrage, which helps to maintain price interaction between basket securities and their underlying assets.

South African ETFs began in the year 2000 with the SATRIX TOP 40 when the ETF market was still unregulated. The ETF landscape in South Africa has been largely protected by regulation since 2004 when ETFs were included under the Collective Investment Schemes Control Act [No. 45 of 2002], but before that, they were largely unregulated. With South Africa having the largest number of ETFs in Africa, this study seeks to ascertain whether regulators should increase scrutiny of the local ETF market due to the risks that are potentially being introduced to the underlying stock market from ETFs. The industry trends are shown by institutional investors utilizing ETFs that are capturing the traditional market for mutual funds and unit trusts due to the low costs of investing in ETFs and, as such, expectations are for further growth of the local ETF market beyond current levels. Already, the developed global ETF market has been facing challenges in the regulation and risk assessment of ETFs. The Flash Crash of 6 May 2010 (NASDAQ, USA), though starting in the futures market, involved $65 \%$ of cancelled trades that belonged to ETFs (SEC, 2010). The Financial Stability Board (FSB) also published a report on the financial stability issues arising from ETFs. The difference in the ETF structures for South Africa as compared to the developed financial market warrant an investigation into the risk implications of local ETFs. Whilst in Europe and the United States (US) more exotic ETFs are in use, e.g. inverse ETFs and leveraged ETFs, South Africa maintains by law the plain vanilla ETF 
structure. The difference in ETFs structure could ultimately lead to variations in the empirical evidence relating to the volatility of the underlying securities. These variations could result from innovations and creativity underlying exotic ETFs offered in Europe and the US compared to plain vanilla ETFs offered in South Africa. Since South Africa is the first African country to develop the ETFs market, this study will provide a platform for both academic and policy engagement in the development of ETFs in emerging markets. This study is particularly important in that it provides a comprehensive understanding of the volatility of securities underlying ETFs and the implications thereof to both investors and regulators while setting a platform for academic debate.

\section{Literature Review}

Although ETFs have been in existence since 1989 (Rompotis, 2010), the literature surrounding them has mostly been on the positives of their performance relative to mutual funds and other actively managed funds. Only recently have there been studies taking a deeper look into the workings of the ETFs with respect to their price efficiency and risks. The earliest studies on ETF mispricing focused on the ETF tracking the Standard \&Poor's 500 Index and one study showed that though there was mispricing of the SPDR ETF, mispricing would disappear within one day and this was not sufficient to provide an exploitable arbitrage opportunity (Elton, Gruber, Comer and Li (2002). The interesting finding in the article by Elton, Gruber, Comer and Li, (2002) was a high positive correlation between the price change in the underlying securities and the amount of trading in shares of the ETF. To this effect, the article concluded that a sufficient amount of arbitrage must be occurring between the ETF market and the market for underlying securities. Similar results have also been produced in the study of Australian ETFs by Gallagher (2005), although the ETF mispricing was seen to be greater than that observed by Elton, Gruber, Comer and Li (2002)on the SPDR ETF.

Studies by Chiang (2005), Lui, Chaing and Cheng (2012) as well as byKayali (2007) highlight how ETF mispricing had a longer lasting effect in emerging markets. ETF mispricing, according to Rompotis (2010) and Aber, Li and Can (2009), is also shown to be greater for ETFs that track foreign indexes. This has been attributed by Gastineau (2002) to currency adjustment for the closing prices. Having established the existence of ETF mispricing, ETF arbitrage is explained by Marshall, Nhut, Nguyen and Nuttawat (2010) as the process of going long (short) the underpriced (overpriced) ETF. The study indicated that the profits to arbitrageurs from ETF arbitrage is economically significant with profits net of spreads averaging 6.7 percent annually over the 2001-2010 period for US-listed ETFs, with profits being even larger for the dollar denominated Swiss-listed S\&P 500 ETF. Ben-David et al. (2012) illustrate an ETF arbitrage process in which an ETF mispriced at a premium will give investors an incentive to buy the underlying securities, and forward these onto the ETF sponsor in return for newly created ETF shares in the exchange. The investors then sell the ETF shares onto the secondary market. This process of arbitrage by investors would generate a decline in the ETF price and potentially increase the Net Asset Value of the ETF, thereby closing out the ETF mispricing. Ben-David et al. (2012) also illustrate a scenario where in the case of an ETF premium; investors could short sell the ETF and buy the underlying asset. ETF arbitrage resulting in profitable trading strategies is also noted in the studies of Engle and Sakar (2006) as well as Petajisto (2011). The result of this cross-market arbitrage is the large trading volumes experienced by ETFs in comparison to their capitalization.

Having established ETF arbitrage, Ben-David et al. (2012) went on to investigate the possibility of shock propagation from the ETF market to the underlying securities. Their analysis was based on US equity securities and concluded that arbitrage activity could result in the propagation of non-fundamental shocks in assets that had an arbitrage relationship. This study supported the work of Shleifer and Vishny (1997) on the limits of arbitrage as it showed that arbitrage activity did not only adjust prices of mispriced securities, but that it could also move prices of securities that are priced correctly. Efficiency in pricing is not improved with arbitrage in the presence of limits to arbitrage, in this case the scarcity of capital. There is not much literature though available on the subject of shock propagation from the ETF market to the underlying securities. Volatility of underlying assets due to the introduction of ETFs has been researched by several researchers. Of note, is the volatility spillover model of Diebold and Yilmaz (2009). They establish an increase in the underlying asset price volatility from the introduction of ETFs from 2003, which coincides with the rise in ETF trading over the period. Krause and Tse (2013) conducted a study on volatility spillovers and concluded 
that spillovers of volatility occur bi-directionally, but the effect is stronger from ETFs to stocks as compared to the reverse.

Concerning the risks associated with ETFs, most studies have been focused around more complex ETFs that have diverged from the original structure of plain vanilla ETFs. These are mostly synthetic ETFs, leveraged ETFs and inverse ETFs, and the concerns surrounding the last of these are centered around the use of total return swaps for collateral on the underlying securities (FSB, 2011). Ramaswamy (2011) postulates that as the volume of ETF products increases, replication strategies can lead to a buildup of systemic risks in financial markets. The study indicates swap counterparties as a source of risk as well as an overestimation of the liquidity of the ETF market. Studies by Hegde and McDermott (2004) also show that findings related to the volatility characteristics of ETFs cannot be generalized to the entire set of recently created ETFs.

\section{Data and Methodology}

Financial time series data is characterized by excess volatility, volatility clustering and leverage effects. Since these effects cannot be properly captured by time series models, like the standard ARCH and GARCH models, volatility models are the most appropriate alternatives for use in this analysis. The data used in this study makes use of daily closing price data of the Satrix Top40 equity ETF and the underlying shares on the JSE. Data for the ETF and component stocks are available from McGregor BFA. However, due to the change in listings from the 1990s to the current period, only shares that are component stocks of ETF for significant periods of time will be used. Normality of the data is tested for in the return series of the price data and not in the actual prices. Tests carried out on the Satrix Top40 ETF will start on their formation date of 27 November 2000 to the last day of trade in 2010. The pre-ETF period starts from 1 January 1995 to the day before ETF inception in 2000 mentioned above. A sample of shares to be tested is selected from the highest weighted shares in the ETF, and the entire constituent of the top 40 shares is expected to be tested in the research design with the exception of those with data that do not meet the criteria requirements to be included in the test sample.

The Autoregressive Conditional Heteroskedasticity (ARCH) of Engle (1982) and the Generalized Autoregressive Conditional Heteroskedasticity (GARCH) of Bollerslev (1986) and different extensions to these models have been extensively used in recent empirical studies investigating volatility in share and asset prices. Use of the ARCH approach on a single return series involves modeling the variance in the return series with its lags as well as past errors that are derived from the regression of the mean return series on lagged versions of itself. Maximum Likelihood Estimations are then used to estimate the coefficients of the model. As documented by Hurditt (2004), normal ARCH and GARCH models have been found to be generally good in the estimation of in-sample parameters and, when the appropriate volatility measure is used, reliable out-ofsample volatility forecasts can be obtained. However, there are a number of problems with the symmetric ARCH and GARCH models. Firstly, they cannot guarantee non-negativity of conditional variance, in which case it becomes necessary to place restrictions on the parameters. Secondly, under certain circumstances these models fail to account for volatility clustering and excess kurtosis in financial series. This is the case if the series volatility is more persistent than that captured by the standard GARCH and ARCH models (Tse, 1998). Thirdly, the model fails to allow any direct feedback between the mean and conditional variance (Brooks, 2008). Lastly, the models cannot capture asymmetry in volatility.

The Exponential Generalized Autoregressive Conditional Heteroskedasticity (E-GARCH) model will be used to measure the volatility in both the ETFs and the underlying stocks. The model proposed by Nelson (1991), is an extension of the standard GARCH models and excels in that it better deals with non-negativity constraints, which may be violated in the standard GARCH models. The need to artificially impose non-negativity constraints on the model parameters is eliminated since the model takes the squared logarithm of the dependent variable. While standard GARCH models cannot account for leverage effects (asymmetric responses of a series to positive and negative shocks), the E-GARCH model also takes this into account (Brooks, 2008). Studies by Lui, Chiang and Cheng (2012) focusing on the use of GARCH models to test volatility, conclude that the E-GARCH model is the most appropriate measure. Other studies by Kim (1994) also conclude that the E-GARCH model is the most descriptive regarding stock index returns.

The basic structure of the symmetric normal GARCH $(1,1)$ from which the E-GARCH is derived is: 
$y_{t}=\mu+\varepsilon_{t}$

$\varepsilon_{t}=u_{t} \sigma_{t}, \quad u_{t} \sim N(0,1)$

$\sigma_{t}^{2}=\alpha_{0}+\alpha_{1} \varepsilon_{t-1}^{2}+\beta \sigma_{t-1}^{2}$

Ordinary least squares (OLS) estimation cannot be used because it does not take into consideration the variance equation. To do this, we need to consider non-linear models. The Student's t-distribution $\log$ likelihood function (LLF) will be used to specify the number of lags where the degrees of freedom $v>2$ controls tail behavior.

$L=-\frac{1}{2} \log \left(\frac{\pi(v-2) \Gamma\left(\frac{v}{2}\right)^{2}}{\Gamma((v+1) / 2)^{2}}\right)-\frac{1}{2} \log \sigma_{t}^{2}-\frac{(v+1)}{2} \log \left(1+\frac{\left(y_{t}-X_{t}^{\prime} \theta\right)^{2}}{\sigma_{t}^{2}(v-2)}\right)$

The E-GARCH model takes the form below:

$\log \left(\sigma_{t}^{2}\right)=\omega+\beta \log \left(\sigma_{t-1}^{2}\right)+\gamma \frac{u_{t-1}}{\sqrt{\sigma_{t-1}^{2}}}+\alpha\left[\frac{\left|u_{t-1}\right|}{\sqrt{\sigma_{t-1}^{2}}}\right]$

Where $\sigma_{t}^{2}$, represents the logged conditional variance or the one-step forward estimate of the variance for the time series; $u_{t}$ represents the error terms of shocks to the time series; $\gamma$, accounts for leverage effects where if it is $<0$, a positive shock would decrease the variance and a negative shock increase the variance. The opposite is true where $\gamma>0$ and shocks are asymmetric if $\gamma \neq 0 . \alpha$, corresponds to the symmetric effect of the model and $\beta$ represents volatility persistence, hence the larger the coefficient, the higher the volatility persistence. The specification above differs from the original model proposed by Nelson (1991) in that Nelson assumes that the error terms follow a Generalized Error Distribution (GED), whilst for the purposes of this study the error distribution has been shown to follow a Student's t-distribution. Though the specification of the model is different from the original one, this model will yield identical estimates except in the intercept term $\omega$, which differs on the distributional assumption and model order.

Interpreting $\gamma$ : The impact of $\gamma$ on conditional volatility can firstly be captured as the scenario where the standardized innovation at $\mathrm{t}-1, \frac{u_{t-1}}{\sqrt{\sigma_{t-1}^{2}}}$ is centered at zero and $\varepsilon_{t-1}=0$ meaning there is no innovation in volatility, $\sigma_{t}$ is a function of previous conditional volatility, $\sigma_{t-1}$. Secondly, in the instance that the standardized innovation equals 1 , the impact on volatility becomes a factor of $\sqrt{e^{1 x-0.0833}}$ which is 0.96 showing a decrease of $4 \%$, which is then transmitted to the standard deviation $\sigma_{t}$. An analysis into the standardized innovations shows that innovations at -2.33 and -1.65 impact volatility by $10.19 \%$ and $7.11 \%$, respectively, whilst standardized innovations at 2.33 and 1.65 impact volatility by $-6.64 \%$ and $-9.25 \%$, respectively, illustrating the left-side skew of large negative news as compared to large positive news showing the leverage effect illustrated by the E-GARCH model.

Interpreting $\alpha$ :Instead of the original model by Nelson (1991) where the absolute standardized innovation $\left[\frac{\left|u_{t-1}\right|}{\sqrt{\sigma_{t-1}^{2}}}-\sqrt{\frac{2}{\pi}}\right]$ and innovations centered at $\sqrt{\frac{2}{\pi}}$ (also 0.79), EViews makes use of $\left[\frac{\left|u_{t-1}\right|}{\sqrt{\sigma_{t-1}^{2}}}\right]$ where the base case $\varepsilon_{t-1}=0$ is used, which can be compared to the impact of $\gamma$. An absolute standardized innovation of 1 yields a change in volatility of a factor of $\sqrt{e^{1 \times 0.2853}}$ which is an increase in volatility of $15.33 \%$. An analysis into the absolute standardized innovations shows that innovations at -2.33 and -1.65 impact volatility by $39.43 \%$ and $26.54 \%$, respectively, whilst standardized innovations at 2.33 and 1.65 impact volatility by $26.54 \%$ and $39.43 \%$, respectively, illustrating symmetric and larger volatility due to the larger coefficient $\alpha$.

Non-negativity constraints must still hold. The coefficients on the ARCH and GARCH terms $(\alpha+\beta)$ must sum to $<1$. If $\alpha+\beta>1$ : series has non-stationary variance, i.e. variance depends on previous values of variance and it would persist $(=1)$ or explode $(>1)$, shocks would not die away and the variance would get larger. Often $(\alpha+$ $\beta$ ) will be very close to one for financial asset returns, i.e. shocks to the conditional variance will be highly persistent. 
Interpreting both $\alpha$ and $\gamma$ : The interpretation of both the variables is shown clearly in Engle and $\mathrm{Ng}$ (1993). In the instances where volatility reacts asymmetrically to negative shocks, the sign for $\gamma$ should be expected to be negative as well as significant. This establishes leverage effects. Combinations of the significance of coefficients can be analyzed as follows:

1. Where $\gamma$ is significant and $\alpha$ not, meaning the absolute size of innovations is not important once the asymmetric impact is accounted for.

2. Where $\gamma$ is not significant and $\alpha$ is, meaning shock increase volatility irrespective of sign, there are no leverage effects.

3. Where $\gamma$ and $\alpha$ are both significant, meaning that once the asymmetric size of the innovations is accounted for the absolute size of the innovation is also important.

\section{Empirical Results and Discussion}

The Satrix Top 40 has been volatile since its inception as shown in Figure 1 below.

Figure 1: Satrix Top 40 Volatility

\section{RTOP40}

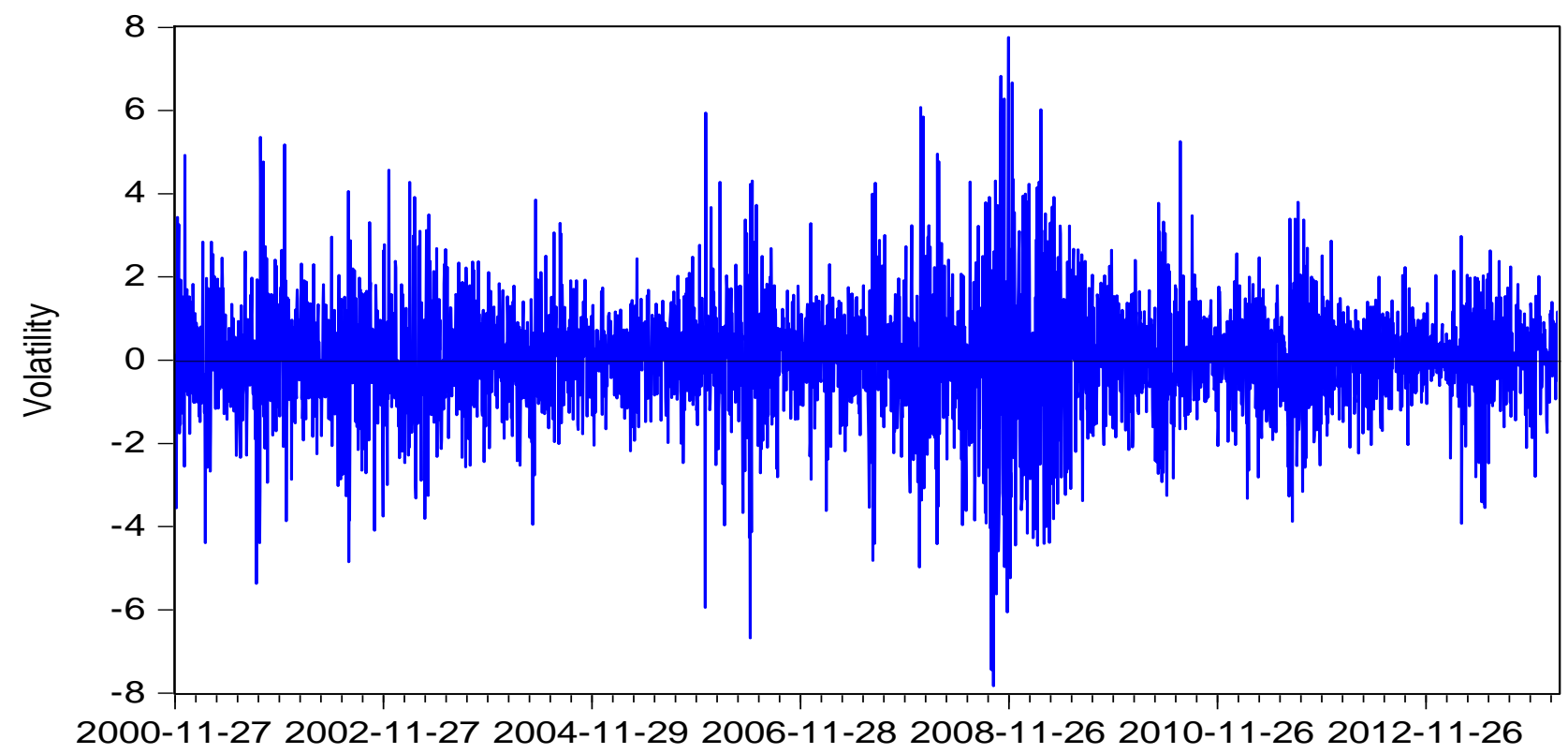

Table 1below shows the summary of the E-GARCH results. Detailed results are in the appendix. The table has three panels of which Panel A shows the volatility of the underlying stocks prior to the establishment of the Satrix 40 ETF; Panel B details the volatility of the underlying stocks after the inclusion of those stocks in the ETF; and finally, Panel C shows how the stocks responded to the global financial crisis and recession from 2008 to 2010. The volatility implications and a detailed discussion follow thereafter.

Interpreting both $\alpha$ and $\gamma$ : For the pre-ETF period in Panel A above, 24 shares have both $\alpha$ and $\gamma$ and both are significant as the absolute value of the innovations is important as the asymmetric impact is accounted for. Twelve shares have a significant $\alpha$ and $\gamma$ is not significant in a scenario where large shocks increase volatility irrespective of sign. For the post-ETF period in Panel B, 17 shares have both $\alpha$ and $\gamma$ and both are significant as the absolute of the innovations is important as the asymmetric impact is accounted for. Twenty shares have a significant $\alpha$ and $\gamma$ is not significant. This is the scenario where large shocks increase volatility irrespective of sign. This indicates a reversal in the balance of the importance of absolute innovations and the symmetric impact as opposed to the situation where only large shocks increase volatility irrespective of the sign. This shows a significant departure from the pre-ETF period. For the recession period in Panel C, 27 
shares have both $\alpha$ and $\gamma$ and both are significant as the absolute of the innovations is important as the asymmetric impact is accounted for. Six shares have a significant $\alpha$ and $\gamma$ is not significant. This is the scenario where large shocks increase volatility irrespective of sign.

Table 1: E-GARCH Results Summary

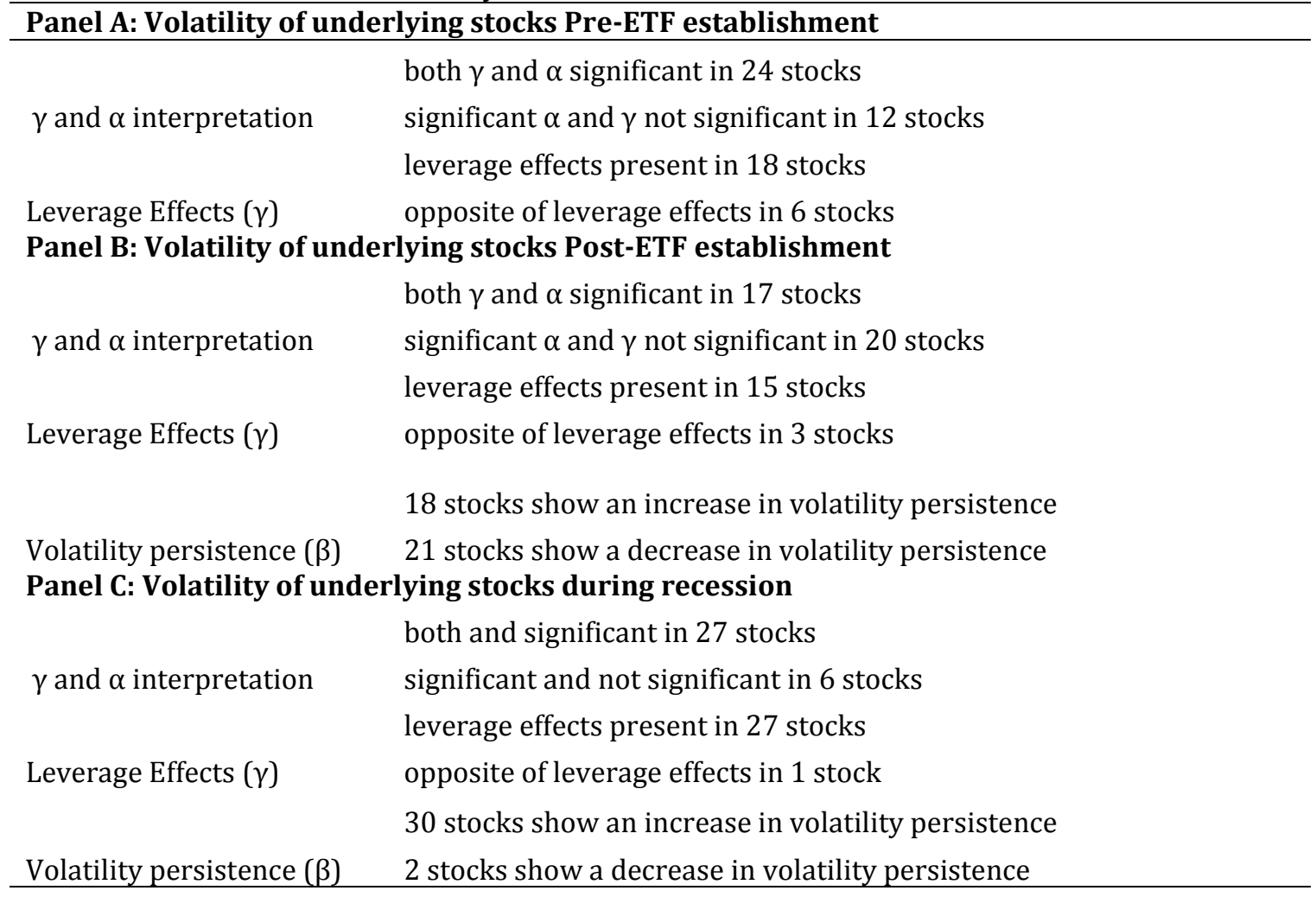

Leverage effects: In the pre-ETF period in Panel A, which is the base scenario on which comparisons will be made, 18 shares in the sample tested, exhibited leverage effects where is $\gamma<0$, and positive shocks decrease the variance and a negative shock increases the variance. Six of the shares had $\gamma>0$, and shocks showing that positive shocks increased the variance and negative shocks decreased the variance. The rest of the 14 shares show insignificant values for $\gamma$ during the sample test period.In the post-ETF period in Panel B, 15 shares in the sample tested, exhibited leverage effects where is $\gamma<0$, and positive shocks decrease the variance and a negative shock increases the variance. Three of the shares had $\gamma>0$, and shocks showing that positive shocks increased the variance and negative shocks decreased the variance. The rest of the 28 shares show insignificant values for $\gamma$ during the sample test period, this shows a big increase in the shares that show an insignificant $\gamma$ coefficient, showing that signs of the innovation in $\gamma$ did not have an impact on volatility. The clear trend shown is the reduction in the number of shares with leverage effects and an increase in the number of shares that had leverage effects as insignificant. It goes along with the certification hypothesis of index shares where the increased public attention influences less asymmetric information and higher liquidity, as shown by Chen, Noronha and Singal (2004). The post ETF period also shows 11 shares that had leverage effects in the pre-ETF period change to insignificant $\gamma$ values, whereas 5 shares change from insignificant $\gamma$ value to having leverage effects in the same time period. This shift in characteristics warrants even further research as the reasons for these changes are still to be examined in academic studies.

In the recession period in Panel C, 27 shares in the sample tested, exhibited leverage effects where $\gamma<0$, and positive shocks decrease the variance and a negative shock increases the variance. One share had $\gamma>0$, and shocks showing that positive shocks increased the variance and negative shocks decreased the variance. The rest of the 5 shares show insignificant values for $\gamma$ coefficient showing that signs of the innovation in $\gamma$ did not have an impact on volatility. The larger number of shares showing leverage effects also reflects the investor sentiment of this period, and shares clearly exhibit leverage effects, a departure from what can be seen in the 
post-ETF period. The introduction of the Satrix Top 40 ETF had significant positive effects on the underlying shares, but the recession period reverted back those characteristics.

Volatility persistence ( $\beta$ ): 18 stocks show an increase in volatility persistence whilst 20 shares show a decrease for the post ETF period. In the recession period, volatility persistence increases in 30 shares whilst there are decreases in only 2 shares. These results are in line with studies by Edwards (1988) and Harris (1989) on index futures component stocks, where volatility declined after creation of the index or there was a negligible increase in volatility. This was further confirmed in the certification hypothesis by Jain (1987) andKaul, Mehrotra and Morck (2000) whose argument is based on the addition of stocks to any index by an agency specializing in company valuations and ratings. Such an announcement would signal positive information on the company leading to positive price effects, potentially from higher liquidity and reductions in asymmetric informationChen et al. (2004).

\section{Conclusion}

The study sought to investigate the volatility characteristics of local ETFs in South Africa. The trading behavior of the shares underlying ETFs, as well as trading activity between the ETF and underlying shares, creates the new characteristics exhibited by shares underlying ETFs. Volatility persistence showed a decrease in the post-ETF period being investigated. This reduction in volatility persistence has been largely attributed to higher liquidity in the shares added to the index ETF as well as higher trading volumes and reductions in asymmetric information. However, in the recession period a lot of volatility persistence was apparent in the model and this relates to the behavior of financial markets during the global financial crisis. Leverage effects are also an intriguing characteristic in the analysis as they changed throughout the model. This change is important as the E-GARCH model used in the analysis specifically does a good job of capturing this phenomenon. Leverage effects decreased in the sample and showed how the negative shocks did not increase volatility. The sign of the shocks became irrelevant as the implications of the share being included in the index took effect. The surge in the trading activity of ETFs is an important source of information flow on the volatility characteristics exhibited in the underlying shares, and these results show a consistent pattern in line with previous research in the change in volatility characteristics of the underlying shares after the inception of ETFs. The differences, however, are in the volatility persistence, which in the case of the Satrix Top 40 has been reduced after the introduction of the index. However, responses of volatility to different shocks show different behavior compared to that previously recorded. The sign of the impact becomes less relevant as the share is held in an index ETF. Rather, the size of the impact becomes more relevant.

The implication of volatility persistence for investors is that a decrease shows a change in the trading activity of stocks included in ETFs. This confirms the certification hypothesis that investors look to the addition of stocks to an index as a positive sign. Investment risk is viewed differently by the market after ETF inception. For fund managers the link between volatility persistence and predictability of the risk return trade-off over the business cycle is crucial for investment decisions over the long-term, as future economic variables can be predicted by current persistence in volatility. This opens up further discussion in the comparisons of active vs passive fund management in South Africa. For regulators and policy formulators, it is evident from the study that a well regulated ETF market reduces the volatility of the underlying securities and could thus provide stability in the financial markets during downturn periods.

Acknowledgements: We would like to thank the reviewers for their comments and suggestions that have helped in shaping this piece of work.

\section{References}

Aber, J. W., Li, D. \& Can, L. (2009). Price volatility and tracking ability of ETFs. Journal of Asset Management, $10,210-221$.

Ben-David, L., Franzoni, F. \& Moussawi, R. (2012). ETFs, arbitrage and shock propagation. Working Paper No. 2011-03-20. Fisher College of Business.

Bollerslev, T. (1986). Generalized Autoregressive Conditional Heteroskedasticity. Journal of Econometrics, 31(3), 307-327. 
Brooks, C. (2008). Introductory Econometrics For Finance, New York: Cambridge University Press.

Chen, H., Noronha, G. \& Singal, V. (2004). The Price response to S\&P 500 index additions and deletions: evidence of asymmetry and a new explanation. Journal of Finance, 59(4), 1901-1929

Chiang, C. C. L. M. S. (2005). Volatility effect of ETFs on the constituents of the underlying Taiwan 50 Index. Applied Financial Economics, 15,1315-1322

SEC. (2010). US Securities \& Exchange Commission (SEC). 2010. Findings regarding the market events of May 6, 2010: Report of the staffs of the CFTC And SEC to the joint advisory committee on emerging regulatory issues, 30 Sept 2010.

Diebold, F. X. \& Yilmaz, K. (2009). Measuring financial asset return and volatility spillovers, with application to global equity markets. Economic Journal, 119, 158-171

Edwards, F. (1988). Does futures trading increase stock market volatility? Financial Analysts Journal, 44(1), 63-69.

Elton, E., Gruber, M., Comer, G. \& Li, K. (2002). Spiders: Where Are the Bugs? The Journal of Business, 75, 453472.

Engle, R. F. (1982). Autoregressive Conditional Heteroscedasticity with Estimates of the Variance of United Kingdom Inflation. Econometrica, 50(4), 987-1008

Engle, R. F. \& Ng, V. K. (1993). Measuring and testing the impact of news on volatility. Journal of Finance, 48, 1749-1778.

Engle, R. F. \& Sakar, D. (2006). Premiums-Discounts and Exchange-Traded Funds. Journal of Derivatives, 13, $27-47$

Gallagher, D. S. R. (2005). The perfomance and trading characteristics of exchange traded funds.: University of New South Wales.

Gastineau, G. (2002). The Exchange-Traded Funds Manual.: New Jersey: John Wiley \& Sons.

Harris, L. (1989). S\&P 500 cash stock price volatilities. Journal of Finance, 44(5),1155-1175

Hegde, S. P. \& McDemortt, J. B. (2004). The market liquidity of Diamonds and Q's, and their underlying stocks. Journal of Banking and Finance, 28, 1043-1067

Hurditt, P. (2004). An assessment of volatility transmission in the Jamaican financial system. Financial Stability Department. Research and Economic Programming Division, Bank of Jamaica.

Jain, P. (1987). The effect on stock price of inclusion or exclusion from the S \& P 500,. Financial AnalystsJournal of Asset Management, 43, 58-65.

Kaul, A, Mehrotra, V. \& Morck, R. (2000). Demand curves for stocks do slope down: new evidence from an index weighted adjustment,. Journal of Finance, 55, 893-912

Kayali, M. (2007). Pricing efficiency of exchange traded funds in Turkey: early evidence from the Dow Jones Istanbul 20. International Research Journal of Finance and Economics, 10, 14-23.

Kim, D. K. S. J. (1994). Alternative models for the conditional heteroscedasticity of stock returns. Journal of Business, 67, 563-598.

Krause, T. \& Tse, Y. (2013). Volatility and return spillovers in Canadian and US industry ETFs. International Review of Economics \& Finance, 25, 244-259

Lin, C. \& Chiang, H. (2005). Volatility effect of ETFs on the constituents of the underlying Taiwan 50 Index. Applied Financial Economics, 15, 1315-1322.

Lui, H. C., Chiang, S. M. \& Cheng, N. Y. P. (2012). Forecasting the volatility of S\&P depositary receipts using GARCH-type models under intraday range based and return based proxy measures. International Review of Economics and Finance, 22, 78-91.

Marshall, B. R., Nhut, H., Nguyen, L. \& Nuttawat, V. (2010). ETF arbitrage. Massey University.

Nelson, D. B. (1991). Conditional hetereskedasticity in asset returns: a new approach. Econometrica, 59, 347370.

Petajisto, A. (2011). Inefficiencies in the pricing of exchange-traded funds.: NYU Stern School of Business.

Ramaswamy, S. (2011). Market structures ans systemic risks of exchange-traded funds. Working Paper. Bank of International Settlements.

Rompotis, G. (2010). Does premium impact exchange-traded funds' returns? Evidence from i-Shares. Journal of Asset Management, 11, 298-308.

Shleifer, A. \& Vishny, R. W. (1997). The Limits of Arbitrage. Journal of Finance, 52, 35-55.

Tse, Y. K. (1998). The conditional heteroscedasticity of the yen-dollar exchange rate. Journal of Applied Econometrics, 13, 49-55. 


\begin{tabular}{|c|c|c|c|c|c|c|c|c|c|}
\hline \multicolumn{10}{|c|}{ E-GARCH (Students t-distribution) on JSE Top 40 constituents of the Satrix } \\
\hline \multirow[b]{2}{*}{ Share } & \multicolumn{3}{|c|}{ Pre-ETF Period } & \multicolumn{3}{|c|}{ Post- ETF Period } & \multicolumn{3}{|c|}{ Recession Period } \\
\hline & Variable & Coefficient & Prob. & Variable & Coefficient & Prob. & Variable & Coefficient & Prob. \\
\hline \multirow[t]{4}{*}{ ABL } & $\Omega$ & -0.06553 & 0.0000 & $\Omega$ & -1.23414 & 0.0000 & $\Omega$ & -0.24325 & 0.0001 \\
\hline & A & 1.06203 & 0.0052 & A & 0.378591 & 0.0000 & A & 0.143566 & 0.0000 \\
\hline & $\Gamma$ & -0.28348 & 0.0119 & $\Gamma$ & -0.04185 & 0.2202 & $\Gamma$ & -0.05754 & 0.0020 \\
\hline & $\mathrm{B}$ & 1.013789 & 0.0000 & $\mathrm{~B}$ & 0.871602 & 0.0000 & $\beta$ & 0.982864 & 0.0000 \\
\hline \multirow[t]{4}{*}{ AGL } & $\Omega$ & -0.38472 & 0.0000 & $\Omega$ & -0.17033 & 0.0065 & $\omega$ & -0.13818 & 0.0000 \\
\hline & A & 0.270319 & 0.0000 & A & 0.092567 & 0.0000 & $\alpha$ & 0.088568 & 0.0000 \\
\hline & $\Gamma$ & -0.02725 & 0.1425 & $\Gamma$ & -0.04272 & 0.0006 & $\gamma$ & -0.07666 & 0.0000 \\
\hline & B & 0.976307 & 0.0000 & B & 0.987126 & 0.0000 & $\beta$ & 0.990619 & 0.0000 \\
\hline \multirow[t]{4}{*}{ AMS } & $\Omega$ & -0.45904 & 0.0000 & $\Omega$ & -1.77573 & 0.0000 & $\omega$ & -0.2143 & 0.0000 \\
\hline & A & 0.242549 & 0.0000 & $\mathrm{~A}$ & 0.395347 & 0.0000 & $\alpha$ & 0.149519 & 0.0000 \\
\hline & $\Gamma$ & -0.02821 & 0.2146 & $\Gamma$ & 0.025719 & 0.4558 & $\gamma$ & -0.0367 & 0.0242 \\
\hline & B & 0.960831 & 0.0000 & $\mathrm{~B}$ & 0.804528 & 0.0000 & $\beta$ & 0.986305 & 0.0000 \\
\hline \multirow[t]{4}{*}{ ANG } & $\Omega$ & -0.617 & 0.0000 & $\Omega$ & -0.32833 & 0.0021 & $\omega$ & -0.11865 & 0.0011 \\
\hline & A & 0.237261 & 0.0000 & A & 0.138397 & 0.0000 & $\alpha$ & 0.104776 & 0.0000 \\
\hline & $\Gamma$ & 0.046126 & 0.0452 & $\Gamma$ & 0.006365 & 0.7159 & $\gamma$ & -0.01081 & 0.4744 \\
\hline & $\mathrm{B}$ & 0.940078 & 0.0000 & B & 0.969945 & 0.0000 & $\beta$ & 0.994901 & 0.0000 \\
\hline \multirow[t]{4}{*}{ ASA } & $\Omega$ & -0.65987 & 0.0000 & $\Omega$ & -0.44366 & 0.0004 & $\omega$ & -0.30532 & 0.0000 \\
\hline & A & 0.385411 & 0.0000 & A & 0.185987 & 0.0000 & $\alpha$ & 0.171598 & 0.0000 \\
\hline & $\Gamma$ & -0.06654 & 0.0133 & $\Gamma$ & -0.02659 & 0.2766 & $\gamma$ & -0.08295 & 0.0001 \\
\hline & B & 0.946402 & 0.0000 & B & 0.961715 & 0.0000 & $\beta$ & 0.978065 & 0.0000 \\
\hline \multirow[t]{4}{*}{ BAW } & $\Omega$ & -0.30928 & 0.0000 & $\Omega$ & -0.45191 & 0.0009 & $\omega$ & -0.18652 & 0.0006 \\
\hline & A & 0.240073 & 0.0000 & A & 0.173587 & 0.0000 & $\alpha$ & 0.099383 & 0.0000 \\
\hline & $\Gamma$ & -0.02409 & 0.2279 & $\Gamma$ & -0.02713 & 0.2135 & $\gamma$ & -0.00188 & 0.8893 \\
\hline & B & 0.980794 & 0.0000 & B & 0.960792 & 0.0000 & $\beta$ & 0.985045 & 0.0000 \\
\hline BIL & $\Omega$ & -0.46819 & 0.0109 & $\Omega$ & -0.2777 & 0.0528 & $\omega$ & -0.18398 & 0.0001 \\
\hline & A & 0.202733 & 0.0000 & $\mathrm{~A}$ & 0.093041 & 0.0004 & $\alpha$ & 0.125629 & 0.0000 \\
\hline & $\Gamma$ & -0.01214 & 0.6892 & $\Gamma$ & -0.01676 & 0.2147 & $\gamma$ & -0.05919 & 0.0003 \\
\hline & B & 0.953478 & 0.0000 & B & 0.973181 & 0.0000 & $\beta$ & 0.988329 & 0.0000 \\
\hline BOE & $\Omega$ & -0.01467 & 0.0000 & $\Omega$ & -1.07519 & 0.0002 & No Data & & \\
\hline & A & 0.190855 & 0.0001 & A & 0.521449 & 0.0000 & & & \\
\hline & $\Gamma$ & -0.2776 & 0.0001 & $\Gamma$ & -0.18858 & 0.0033 & & & \\
\hline & $\beta$ & 1.001427 & 0.0000 & B & 0.913581 & 0.0000 & & & \\
\hline BVT & $\omega$ & 0.006576 & 0.0167 & $\Omega$ & -1.36212 & 0.0002 & $\omega$ & -0.26806 & 0.0000 \\
\hline & $\alpha$ & 2.270912 & 0.0008 & $\mathrm{~A}$ & 0.274379 & 0.0000 & $\alpha$ & 0.117228 & 0.0000 \\
\hline & $\gamma$ & 1.188885 & 0.1070 & $\Gamma$ & -0.02155 & 0.5235 & $\gamma$ & -0.10612 & 0.0000 \\
\hline & $\beta$ & 0.998629 & 0.0000 & B & 0.860408 & 0.0000 & $\beta$ & 0.977726 & 0.0000 \\
\hline CFR & $\omega$ & -0.92125 & 0.0000 & $\Omega$ & -0.19283 & 0.0002 & $\omega$ & -0.23448 & 0.0001 \\
\hline & $\alpha$ & 0.371944 & 0.0000 & A & 0.106018 & 0.0000 & $\alpha$ & 0.100525 & 0.0000 \\
\hline & $\gamma$ & -0.03004 & 0.2786 & $\Gamma$ & -0.06378 & 0.0001 & $\gamma$ & -0.03841 & 0.0358 \\
\hline & $\beta$ & 0.919132 & 0.0000 & B & 0.985855 & 0.0000 & $\beta$ & 0.979758 & 0.0000 \\
\hline СРX & $\omega$ & 0.008073 & 0.0000 & $\Omega$ & -0.10925 & 0.0015 & No Data & & \\
\hline & $\alpha$ & -0.03727 & 0.0000 & $\mathrm{~A}$ & -0.02163 & 0.0866 & & & \\
\hline & $\gamma$ & 0.118334 & 0.0000 & $\Gamma$ & -0.05997 & 0.0000 & & & \\
\hline & $\beta$ & 1.000345 & 0.0000 & B & 0.984138 & 0.0000 & & & \\
\hline $\mathrm{CRH}$ & $\omega$ & 0.252029 & 0.3507 & $\Omega$ & -0.17998 & 0.0000 & No Data & & \\
\hline & $\alpha$ & 119.2568 & 0.2396 & A & 0.661822 & 0.0316 & & & \\
\hline & $\gamma$ & 3.619248 & 0.6546 & $\Gamma$ & 0.775345 & 0.0305 & & & \\
\hline & $\beta$ & 0.862942 & 0.0000 & B & 0.995527 & 0.0000 & & & \\
\hline CSO & $\omega$ & -0.88697 & 0.1061 & $\Omega$ & -0.69404 & 0.0025 & $\omega$ & -0.21341 & 0.0002 \\
\hline & $\alpha$ & 0.247747 & 0.0467 & $\mathrm{~A}$ & 0.183727 & 0.0000 & $\alpha$ & 0.134969 & 0.0000 \\
\hline & $\gamma$ & -0.01892 & 0.7960 & $\Gamma$ & 0.015453 & 0.5115 & $\gamma$ & -0.0141 & 0.4196 \\
\hline & $\beta$ & 0.9105 & 0.0000 & B & 0.935727 & 0.0000 & $\beta$ & 0.98565 & 0.0000 \\
\hline DDT & $\omega$ & -0.13569 & 0.0000 & $\Omega$ & -0.15455 & 0.0003 & $\omega$ & -0.1909 & 0.0001 \\
\hline & $\alpha$ & 0.678527 & 0.0066 & A & 0.131615 & 0.0000 & $\alpha$ & 0.523411 & 0.0000 \\
\hline & $\gamma$ & -0.15481 & 0.0595 & $\Gamma$ & -0.01568 & 0.2560 & $\gamma$ & -0.07041 & 0.0145 \\
\hline & $\beta$ & 0.999281 & 0.0000 & B & 0.991792 & 0.0000 & $\beta$ & 1.023563 & 0.0000 \\
\hline DTC & $\omega$ & 0.037985 & 0.0000 & $\Omega$ & -0.10226 & 0.0003 & $\omega$ & -0.38771 & 0.0007 \\
\hline & $\alpha$ & -0.16632 & 0.0000 & $\mathrm{~A}$ & 0.101912 & 0.0000 & $\alpha$ & 0.200275 & 0.0000 \\
\hline & $\gamma$ & -0.07406 & 0.0793 & $\Gamma$ & -0.01957 & 0.0502 & $\gamma$ & -0.02959 & 0.2036 \\
\hline & $\beta$ & 0.992985 & 0.0000 & B & 0.995712 & 0.0000 & $\beta$ & 0.964764 & 0.0000 \\
\hline FDS & $\omega$ & -0.01111 & 0.0000 & $\Omega$ & -0.48578 & 0.0088 & No Data & & \\
\hline & $\alpha$ & 16.30044 & 0.0000 & $\mathrm{~A}$ & 0.319078 & 0.1918 & & & \\
\hline & $\gamma$ & -13.5871 & 0.0000 & $\Gamma$ & 0.01083 & 0.9315 & & & \\
\hline
\end{tabular}




\begin{tabular}{|c|c|c|c|c|c|c|c|c|c|}
\hline & $\beta$ & 0.998712 & 0.0000 & B & 0.898177 & 0.0000 & & & \\
\hline \multirow[t]{4}{*}{ FSR } & $\omega$ & 0.006259 & 0.0004 & $\Omega$ & -0.95663 & 0.0003 & $\omega$ & -0.29641 & 0.0003 \\
\hline & $\alpha$ & 2.041523 & 0.0002 & A & 0.246802 & 0.0000 & $\alpha$ & 0.154415 & 0.0000 \\
\hline & $\gamma$ & 1.486489 & 0.0005 & $\Gamma$ & -0.05305 & 0.0376 & $\gamma$ & -0.04551 & 0.0375 \\
\hline & $\beta$ & 0.998428 & 0.0000 & B & 0.905742 & 0.0000 & $\beta$ & 0.976815 & 0.0000 \\
\hline \multirow[t]{4}{*}{ GFI } & $\omega$ & -0.35922 & 0.0002 & $\Omega$ & -0.09367 & 0.0056 & $\omega$ & -0.13151 & 0.0002 \\
\hline & $\alpha$ & 0.185406 & 0.0000 & A & 0.070137 & 0.0003 & $\alpha$ & 0.12177 & 0.0000 \\
\hline & $\gamma$ & -0.01905 & 0.3230 & $\Gamma$ & 0.020959 & 0.0548 & $\gamma$ & -0.03321 & 0.0479 \\
\hline & $\beta$ & 0.969617 & 0.0000 & B & 0.994517 & 0.0000 & $\beta$ & 0.99513 & 0.0000 \\
\hline \multirow[t]{4}{*}{ GSC } & $\omega$ & -0.17444 & 0.0001 & $\Omega$ & -13.6487 & 0.3878 & No Data & & \\
\hline & $\alpha$ & 0.206348 & 0.0000 & A & 0.738928 & 0.6871 & & & \\
\hline & $\gamma$ & -0.06742 & 0.0024 & $\Gamma$ & -0.22575 & 0.8906 & & & \\
\hline & $\beta$ & 0.992326 & 0.0000 & B & 0.027427 & 0.9812 & & & \\
\hline \multirow[t]{4}{*}{ IMP } & $\omega$ & -1.36941 & 0.0000 & $\Omega$ & -0.18654 & 0.0004 & $\omega$ & -0.20332 & 0.0001 \\
\hline & $\alpha$ & 0.505115 & 0.0000 & A & 0.109573 & 0.0000 & $\alpha$ & 0.136284 & 0.0000 \\
\hline & $\gamma$ & 0.00753 & 0.8481 & $\Gamma$ & -0.03578 & 0.0122 & $\gamma$ & -0.03443 & 0.0820 \\
\hline & $\beta$ & 0.850472 & 0.0000 & B & 0.986421 & 0.0000 & $\beta$ & 0.986344 & 0.0000 \\
\hline \multirow[t]{4}{*}{ INL } & $\omega$ & 0.010594 & 0.0003 & $\Omega$ & -1.07225 & 0.0002 & $\omega$ & -0.26 & 0.0000 \\
\hline & $\alpha$ & 1.170331 & 0.0425 & A & 0.256997 & 0.0000 & $\alpha$ & 0.1738 & 0.0000 \\
\hline & $\gamma$ & -1.34384 & 0.0149 & $\Gamma$ & -0.06114 & 0.0323 & $\gamma$ & -0.06267 & 0.0022 \\
\hline & $\beta$ & 0.997572 & 0.0000 & B & 0.884659 & 0.0000 & $\beta$ & 0.983244 & 0.0000 \\
\hline \multirow[t]{4}{*}{ IPL } & $\omega$ & -0.01575 & 0.0000 & $\Omega$ & -1.18004 & 0.0002 & $\omega$ & -0.38819 & 0.0001 \\
\hline & $\alpha$ & -0.03992 & 0.0000 & A & 0.283032 & 0.0000 & $\alpha$ & 0.168555 & 0.0000 \\
\hline & $\gamma$ & -0.11634 & 0.0000 & $\Gamma$ & -0.03696 & 0.1933 & $\gamma$ & -0.04809 & 0.0182 \\
\hline & $\beta$ & 0.99326 & 0.0000 & B & 0.882291 & 0.0000 & $\beta$ & 0.965548 & 0.0000 \\
\hline \multirow[t]{4}{*}{ JNC } & $\omega$ & -0.93994 & 0.0000 & $\Omega$ & -1.11151 & 0.0000 & $\omega$ & -0.37732 & 0.0000 \\
\hline & $\alpha$ & 0.449958 & 0.0000 & A & 0.32632 & 0.0000 & $\alpha$ & 3.959849 & 0.0000 \\
\hline & $\gamma$ & 0.083839 & 0.0049 & $\Gamma$ & 0.20576 & 0.0000 & $\gamma$ & 0.038698 & 0.7330 \\
\hline & $\beta$ & 0.90317 & 0.0000 & B & 0.869429 & 0.0000 & $\beta$ & 1.017565 & 0.0000 \\
\hline \multirow[t]{4}{*}{ LGL } & $\omega$ & -0.18191 & 0.0001 & $\Omega$ & -1.43804 & 0.0064 & $\omega$ & -0.4823 & 0.0028 \\
\hline & $\alpha$ & 0.116882 & 0.0000 & A & 0.225258 & 0.0004 & $\alpha$ & 0.197889 & 0.0001 \\
\hline & $\gamma$ & -0.00983 & 0.5585 & $\Gamma$ & -0.0066 & 0.8577 & $\gamma$ & -0.09169 & 0.0136 \\
\hline & $\beta$ & 0.986056 & 0.0000 & B & 0.84239 & 0.0000 & $\beta$ & 0.95715 & 0.0000 \\
\hline \multirow[t]{4}{*}{ MHH } & $\omega$ & -0.53087 & 0.0000 & $\Omega$ & -0.14311 & 0.0280 & No Data & & \\
\hline & $\alpha$ & 1.442064 & 0.0349 & A & 0.134861 & 0.0012 & & & \\
\hline & $\gamma$ & 0.244567 & 0.0843 & $\gamma$ & -0.06963 & 0.0067 & & & \\
\hline & $\beta$ & 0.935105 & 0.0000 & $\beta$ & 0.992962 & 0.0000 & & & \\
\hline \multirow[t]{4}{*}{ MTC } & $\omega$ & 0.041118 & 0.0000 & $\omega$ & -0.14141 & 0.0003 & No Data & & \\
\hline & $\alpha$ & -0.19388 & 0.0000 & $\alpha$ & 0.090969 & 0.0001 & & & \\
\hline & $\gamma$ & 0.201927 & 0.0000 & $\gamma$ & 0.001785 & 0.9317 & & & \\
\hline & $\beta$ & 0.990139 & 0.0000 & $\beta$ & 0.989021 & 0.0000 & & & \\
\hline MTN & $\omega$ & 1.929643 & 0.9459 & $\omega$ & -2.37769 & 0.0000 & $\omega$ & -0.36773 & 0.0009 \\
\hline & $\alpha$ & 108.9724 & 0.9349 & $\alpha$ & 0.483583 & 0.0000 & $\alpha$ & 0.195318 & 0.0000 \\
\hline & $\gamma$ & 11.50295 & 0.9353 & $\gamma$ & -0.03425 & 0.4658 & $\gamma$ & -0.06135 & 0.0127 \\
\hline & $\beta$ & -0.18948 & 0.5586 & $\beta$ & 0.738442 & 0.0000 & $\beta$ & 0.971449 & 0.0000 \\
\hline NED & $\omega$ & -0.26413 & 0.0000 & $\omega$ & -0.19772 & 0.0142 & $\omega$ & -0.26319 & 0.0005 \\
\hline & $\alpha$ & 0.206467 & 0.0000 & $\alpha$ & 0.067668 & 0.0021 & $\alpha$ & 0.155507 & 0.0000 \\
\hline & $\gamma$ & -0.06794 & 0.0004 & $\gamma$ & -0.04187 & 0.0056 & $\gamma$ & -0.04713 & 0.0246 \\
\hline & $\beta$ & 0.983716 & 0.0000 & $\beta$ & 0.981634 & 0.0000 & $\beta$ & 0.981519 & 0.0000 \\
\hline NPK & $\omega$ & -0.40951 & 0.0000 & $\omega$ & -0.23544 & 0.0016 & $\omega$ & -0.80196 & 0.0000 \\
\hline & $\alpha$ & 0.286286 & 0.0000 & $\alpha$ & 0.107626 & 0.0000 & $\alpha$ & 0.323157 & 0.0000 \\
\hline & $\gamma$ & -0.02213 & 0.3643 & $\gamma$ & -0.01636 & 0.3920 & $\gamma$ & -0.0585 & 0.0629 \\
\hline & $\beta$ & 0.968144 & 0.0000 & $\beta$ & 0.981389 & 0.0000 & $\beta$ & 0.928133 & 0.0000 \\
\hline NPN & $\omega$ & -0.14229 & 0.0000 & $\omega$ & -0.7484 & 0.0000 & $\omega$ & -0.29163 & 0.0001 \\
\hline & $\alpha$ & 2.029601 & 0.0197 & $\alpha$ & 0.316901 & 0.0000 & $\alpha$ & 0.109934 & 0.0000 \\
\hline & $\gamma$ & -0.55491 & 0.0289 & $\gamma$ & -0.03208 & 0.2278 & $\gamma$ & -0.08903 & 0.0000 \\
\hline & $\beta$ & 1.012343 & 0.0000 & $\beta$ & 0.930258 & 0.0000 & $\beta$ & 0.972789 & 0.0000 \\
\hline OML & $\omega$ & -0.26717 & 0.1373 & $\omega$ & -0.19723 & 0.0003 & $\omega$ & -0.20282 & 0.0000 \\
\hline & $\alpha$ & 0.125005 & 0.0282 & $\alpha$ & 0.107141 & 0.0000 & $\alpha$ & 0.159542 & 0.0000 \\
\hline & $\gamma$ & 0.000499 & 0.9909 & $\gamma$ & -0.0518 & 0.0004 & $\gamma$ & -0.04497 & 0.0120 \\
\hline & $\beta$ & 0.978217 & 0.0000 & $\beta$ & 0.985761 & 0.0000 & $\beta$ & 0.989455 & 0.0000 \\
\hline REM & $\omega$ & -2.91252 & 0.4210 & $\omega$ & -0.74558 & 0.0378 & $\omega$ & -0.63876 & 0.0024 \\
\hline & $\alpha$ & -0.04606 & 0.9282 & $\alpha$ & 0.119974 & 0.0035 & $\alpha$ & 0.117751 & 0.0002 \\
\hline & $\gamma$ & -0.37609 & 0.2877 & $\gamma$ & 0.009836 & 0.7076 & $\gamma$ & 0.042064 & 0.0855 \\
\hline & $\beta$ & 0.628359 & 0.1381 & $\beta$ & 0.92241 & 0.0000 & $\beta$ & 0.932153 & 0.0000 \\
\hline RMH & $\omega$ & 0.013456 & 0.0000 & $\omega$ & -0.64131 & 0.0006 & $\omega$ & -0.33998 & 0.0000 \\
\hline & $\alpha$ & 1.988357 & 0.0007 & $\alpha$ & 0.217089 & 0.0000 & $\alpha$ & 0.184932 & 0.0000 \\
\hline & $\gamma$ & 1.547724 & 0.0100 & $\gamma$ & -0.0617 & 0.0157 & $\gamma$ & -0.06612 & 0.0033 \\
\hline & $\beta$ & 0.997589 & 0.0000 & $\beta$ & 0.939848 & 0.0000 & $\beta$ & 0.974174 & 0.0000 \\
\hline
\end{tabular}




\begin{tabular}{|c|c|c|c|c|c|c|c|c|c|}
\hline \multirow[t]{4}{*}{ SAB } & $\omega$ & -0.39026 & 0.0000 & $\omega$ & -0.21915 & 0.0154 & $\omega$ & -0.24137 & 0.0003 \\
\hline & $\alpha$ & 0.259749 & 0.0000 & $\alpha$ & 0.085118 & 0.0005 & $\alpha$ & 0.118452 & 0.0000 \\
\hline & $\gamma$ & -0.04922 & 0.0288 & $\gamma$ & -0.01053 & 0.4496 & $\gamma$ & -0.06022 & 0.0021 \\
\hline & $\beta$ & 0.974021 & 0.0000 & $\beta$ & 0.981378 & 0.0000 & $\beta$ & 0.981692 & 0.0000 \\
\hline \multirow[t]{4}{*}{ SAP } & $\omega$ & -0.26703 & 0.0000 & $\omega$ & -1.25962 & 0.0001 & $\omega$ & -0.14278 & 0.0000 \\
\hline & $\alpha$ & 0.347333 & 0.0000 & $\alpha$ & 0.29722 & 0.0000 & $\alpha$ & 0.106323 & 0.0000 \\
\hline & $\gamma$ & -0.04832 & 0.0545 & $\gamma$ & -0.08991 & 0.0053 & $\gamma$ & -0.06127 & 0.0001 \\
\hline & $\beta$ & 0.988936 & 0.0000 & $\beta$ & 0.864423 & 0.0000 & $\beta$ & 0.991291 & 0.0000 \\
\hline \multirow[t]{4}{*}{ SBK } & $\omega$ & -0.04728 & 0.0000 & $\omega$ & -0.75539 & 0.0029 & $\omega$ & -0.31271 & 0.0000 \\
\hline & $\alpha$ & 0.212436 & 0.0027 & $\alpha$ & 0.188298 & 0.0000 & $\alpha$ & 0.181536 & 0.0000 \\
\hline & $\gamma$ & -0.10271 & 0.0276 & $\gamma$ & -0.01948 & 0.3594 & $\gamma$ & -0.06986 & 0.0020 \\
\hline & $\beta$ & 0.999554 & 0.0000 & $\beta$ & 0.924673 & 0.0000 & $\beta$ & 0.977664 & 0.0000 \\
\hline \multirow[t]{4}{*}{ SLM } & $\omega$ & -1.58847 & 0.0080 & $\omega$ & -4.65728 & 0.0000 & $\omega$ & -0.43562 & 0.0000 \\
\hline & $\alpha$ & 0.387679 & 0.0000 & $\alpha$ & 0.413115 & 0.0000 & $\alpha$ & 0.230071 & 0.0000 \\
\hline & $\gamma$ & -0.10128 & 0.0718 & $\gamma$ & 0.012135 & 0.7887 & $\gamma$ & -0.05763 & 0.0224 \\
\hline & $\beta$ & 0.827691 & 0.0000 & $\beta$ & 0.463222 & 0.0002 & $\beta$ & 0.967687 & 0.0000 \\
\hline \multirow[t]{4}{*}{ SOL } & $\omega$ & -0.32384 & 0.0000 & $\omega$ & -1.23815 & 0.0053 & $\omega$ & -0.20871 & 0.0000 \\
\hline & $\alpha$ & 0.219702 & 0.0000 & $\alpha$ & 0.185005 & 0.0002 & $\alpha$ & 0.136933 & 0.0000 \\
\hline & $\gamma$ & -0.05052 & 0.0042 & $\gamma$ & 0.027002 & 0.3159 & $\gamma$ & -0.05873 & 0.0012 \\
\hline & $\beta$ & 0.977779 & 0.0000 & $\beta$ & 0.858528 & 0.0000 & $\beta$ & 0.986449 & 0.0000 \\
\hline \multirow[t]{4}{*}{ TBS } & $\omega$ & -0.26558 & 0.0000 & $\omega$ & -1.80517 & 0.0008 & $\omega$ & -0.18312 & 0.0018 \\
\hline & $\alpha$ & 0.310105 & 0.0000 & $\alpha$ & 0.297821 & 0.0000 & $\alpha$ & 0.096758 & 0.0000 \\
\hline & $\gamma$ & -0.07232 & 0.0046 & $\gamma$ & 0.0815 & 0.0572 & $\gamma$ & -0.04414 & 0.0163 \\
\hline & $\beta$ & 0.987749 & 0.0000 & $\beta$ & 0.804411 & 0.0000 & $\beta$ & 0.98667 & 0.0000 \\
\hline \multirow[t]{4}{*}{ VNF } & $\omega$ & -4.00281 & 0.0443 & $\omega$ & -0.42228 & 0.0017 & $\omega$ & -1.51682 & 0.0000 \\
\hline & $\alpha$ & -0.42483 & 0.4014 & $\alpha$ & 0.155559 & 0.0000 & $\alpha$ & 2.957146 & 0.0000 \\
\hline & $\gamma$ & 0.625906 & 0.1241 & $\gamma$ & -0.04591 & 0.0362 & $\gamma$ & -2.21971 & 0.0000 \\
\hline & $\beta$ & 0.359143 & 0.1917 & $\beta$ & 0.962742 & 0.0000 & $\beta$ & 0.96521 & 0.0000 \\
\hline
\end{tabular}

